4 Chapman PJ, Nasser BP. Attitudes to mouthguards and prevalence of orofacial injuries in four teams competing at the second Rugby World Cup. Br F Sports Med 1993;27: the secon.

5 Croll TP. Custom-fitted protective mouthguards. $f$ Esthet Dent 1992;4:143-7.

6 Milward PJ, Jagger RG. A laminating procedure for thermoformed mouthguards. $\mathcal{F}$ Prosth Dent 1992:68:862-3.

7 Park JB, Shaull KL, Overton B, Donly KJ. Improving mouthguards. F Prosth Dent 1994;72:373-80.

8 De Wijn JR, Vrijhoef MMA, Versteegh PA, Stassen HP Linn EW. A mechanical investigation to the functioning of

\section{Commentary}

This article sets out to develop a standard test procedure for mouthguard assessment. A test rig is described, results taken, appropriate forces discussed, and a standardised method suggested. This should allow comparison between different types of mouth guard and improvements in design developed in the laboratory before being tested in the field.

R W KENDRICK mouthguards. Proceedings of 3rd General Meeting of the Europen Society of Biomechanics. In: Huiskes R, Van Campen D, De Wijn JR, eds. Biomechanics: principles and applications. The Hague: Martinus Nijhoff, 1982:451-58.

9 Matsuno T, Korshi M. Fracture toughness of porous sintered bodies of hydroxyapatite. Chem Lett 1992;12: 2335-8.

10 Takagi M, Mochida M, Uchida N, Saito K, Uematsu K. Filter cake forming and hot isostatic pressing for TZP199-203. dispersed hydroxyapatite composite. $f$ Material Sci 1992;3

\title{
Cor, what a team!
}

At a recent interview, when asked to choose his greatest ever team performance, the former President of FIFA (Fictitious International Football Association) Sir Stanley Rous Sarcoma chose the 1997 Plymouth Argyll Robertson Pupil FC (a.k.a. "the Medics"). Their nickname arose from the clinical way they disposed of visitors to their home ground at Weber Parkes (Syndrome City). "The Medics" were no less successful away from home due to the surgical precision with which they dissected host defences on the ephemeral break. The club had already become financially extremely successful due to their Chairman Martin "Starr" Edwards-"Val(v)ue for money is the heart of the game" was his motto. The allimportant style of play, however, was dictated by the team's manager Graham Turner Syndrome (before his subsequent fall from grace due to involvement in the "XO" sex scandal). The team's crowning glory was winning the 1997 European Cup Final when a dramatic last minute penalty helped defeat the German side Bayer Munich at Lisbon's famous "Stadium of Light-Chained Paraprotein".

\section{The team (nicknames in brackets)}

1 Bob Wilson (Storage Disease) - initially an adolescent delinquent, he says he learnt the art of goalkeeping at an approved school (Lillishall) in order to avoid later excessive "Copper" problem.

2 Robert Jones (Procedure)-performances belied severe ankle instability problems.

3 Earl Barrett (Oesophagus) - often produced deep penetrating holes in defences.

4 Alan Hansen (Bacillus) - never seemed to feel pain when tackling opponents.

5 Tony Adams-Later of Arsenal, and formerly with Stoke, Adam's attacks were impressive but infrequent.

6 Jimmy Hill (Sachs Lesion)-the "hatchet-man" of the team.
7 Anders Limpar (Skin Disease - a great acquisition from the Swedish club Adipose Tuberosa Simplex FC.

8 Andy Grey-Turner's greatest signing.

9 Kevin Campbell (de Morgan) - always dependable from "the Spot".

10 Ian Wright-great goalscorer before his career was "Stained" by involvement in X-rated "blood films".

11 Robbie Fowler -Solution to most striking problems especially against the Arsen(ic)al.

\section{Subs}

12 Chris Bart-Williams (Haemoglobin)the perpetual baby of the side.

13 Paul Allen (Test) - great goal scorer but occasionally fades away when there are difficulties with adequate supply.

14 George Berry (Aneurysm)-once famed for his deft clips at corners now not so good in air owing to serious head injury.

15 Peter Osgood (Schlatter Disease)overcame knee injury early in career to later become a superstar.

16 Mark Hughes - reflex striking at its best but least said about private life! What a great team-assembled for less than the money it cost to buy one of the Newcastle United club feet! So famed was this team that at the end of their careers Wilson, Hansen, Hill, and Grey all became TV presenters on BBC's "Cross-Match of the Day". Ah, who will ever forget that night in Lisbon when Jones had to score that penalty "for the team" against the famed German International keeper Heinz (bodies)-Reidel (lobe) Bence. Jones showed nerves of Steel (-RichardsonOlsezewski) when slotting home that last minute spot-kick hence such a situation has gone down in football folklore as the Bence-Jones (Pro-team) Test.

W W GIBBON Football correspondent The Sun NHS (mis) Trust 